\title{
KRISTALISASI KEPEMIMPINAN BARNABAS DALAM KONTEKS RAKYAT INDONESIA MEMILIH PEMIMPIN PADA PEMILU 2019
}

\author{
Dr. Adolf Bastian Simamora
}

\begin{abstract}
Abstrak
Pesta demokrasi pada Pemilu April 2019 sudah semakin mendekat. Fokus dan topik dalam pemilu bukan saja bagaimana agar sukses terlaksana, namun yang sangat penting adalah apakah dan bagaimana rakyat mengetahui dan memahami siapa calon pemimpin yang akan mereka pilih. Tulisan ini mendeskripsikan kristalisasi kepemimpinan Barnabas dalam konteks rakyat Indonesia akan memilih pemimpin pada Pemilu April 2019 ini. Pemilu ini akan dilaksanakan secara serentak di seluruh negeri Indonesia. Momen ini sangat penting sebab akan menentukan bagaimana masa depan bangsa Indonesia. Sebab rakyat akan memilih siapa yang menjadi presiden dan wakil presiden untuk lima tahun ke depan. Selain itu, rakyat juga akan memilih para anggota DPR, anggota DPD, anggota DPRD untuk masa periode lima tahun mendatang. Pemilu 2019 ini dilakasanakan secara serempak di seluruh negeri Indonesia. Oleh karena itu, melalui tulisan ini penulis akan mendeskripsikan suatu solusi terhadap persoalan tentang bagaimana kriteria pemimpin yang berkualitas. Pada Bab 1, Pendahuluan mendeskripsikan Pemilu, dan masalah kepemimpinan serta harapan masyarakat terhadap pemimpin mereka yaitu presiden dan wakil presiden, anggota DPR, DPD, dan DPRD . Bab 2, Pembahasan tentang kristalisasi kepemimpinan Barnabas bersumber dari kajian eksegesis teks Kisah Para Rasul 4 : 36-37 ;11:19-30. Bab 3, relevansi dalam konteks rakyat Indonesia memilih pemimpin pada pemilu 2019. Apa dan bagaimana rakyat Indonesia memilih atau mencari pemimpin yang baik, amanah, taqwa yang memiliki integritas dan kompetensi yang dapat dipercaya dan diandalkan oleh rakyat Indonesia. Bab 4, penutup yang mendeskripsikan kesimpulan dan saran, dimana penulis menyimpulkan bahwa kepemimpinan Barnabas patut menjadi model dan pendekatan kepemimpinan dalam konteks rakyat Indonesia memilih pemimpinnya untuk masa lima tahun ke depan pada Pemilu 2019 ini.
\end{abstract}

Kata-kata kunci : Pemilu 2019, Kristalisasi Kepemimpinan Barnabas, relevansi

\section{BAB I. PENDAHULUAN}

\section{A. Pemilu 2019}

Tahapan formal Pemilu 2019 yang meliputi pemilihan presiden dan wakilnya, anggota DPR, DPD, DPRD telah resmi dimulai dengan kampanye, sejak minggu (23/9) dan akan berpuncak pada pencoblosan, Jumat 19 April 2019. Untuk pertama kalinya pemilihan presiden dan wakilnya dan legislatif dilakukan serempak. Biaya penyelenggaraan Pemilu 2019 ini dianggarkan sebesar 24,8 triliun rupiah. Ini meningkat sekitar 700 miliar dibandingkan Pemilu 2014. KPU mengeluarkan delapan aturan main kampanye Pemilu 2019. Belum lagi dana yang 
dikeluarkan oleh para kontestan Pemilu. Kita harus memahami betapa besarnya biaya untuk mencari para pemimpin di negara ini. Karena itu kita harus gunakan momen ini dengan bijak dan cerdas. Kontestan Pemilu 2019 yang ikut bertarung ada 16 Partai (12 lama dan 4 yang baru). Yang akan dipilih kali ini sepasang presiden dan wakil presiden, 575 anggota DPR RI, 136 anggota DPD, 2207 anggota DPR Provinsi dan 17.610 anggota DPRD Kota/Kabupaten, dengan jumlah pemilih 185,732,093 orang pemilih yang terdiri dari 92.802 .671 pemilih lakilaki dan 92.929.422 pemilih perempuan, yang akan memilih di 805.075 TPS. Diantara ribuan calon, terdapat 38 mantan terpidana kasus korupsi (https ://www.bbc.com> indonesia, 22/2/2019.16.45 WIB).

\section{B. Permasalahan Kepemimpinan}

Menjadi seorang pemimpin dan memiliki sebuah jabatan merupakan impian semua orang kecuali sedikit dari mereka yang dirahmati oleh Allah. Mayoritas orang justru menjadikannya sebagai ajang rebutan, yaitu jabatan-jabatan politik sebagai anggota DPRD, DPR, Bupati, Gubernur atau Presiden. Permasalahan yang ada pada masa kini antara lain: masih banyak rakyat yang golput, berita atau kampanye hoaks, ujaran kebencian, fitnah dan sebagainya hal-hal yang negatif. Masyarakat kecewa karena janji-janji sewaktu kampanye tidak dipenuhi baik oleh rakyat melihat, banyak pemimpin yang menjabat kini terlibat masalah kasus korupsi, moralitas, malas, buruk integritas dan minus prestasi dan kompetensi. Apakah masyarakat masih percaya dengan Institusi Partai Politik? (http s://m.kumparan.com, 22/2/2019, 17.25 WIB).

\section{Pemimpin Harapan Rakyat}

Bagaimana sosok pemimpin bangsa Indonesia yang diimpikan atau diharapkan oleh rakyat? Sosok seorang pemimpin untuk Indonesia menurut penulis (Apriani Mariani, www.darwinsaleh.com), 22/2/2019, 16.42) hendaknya yang berbudi pekerti luhur, berjiwa Pancasila, amanah, cerdas, mementingkan kepentingan rakyatnya dari pada kepentingan pribadi, keluarga dan kerabatnya, berjiwa patriotisme dan nasionalisme, suri tauladan bagi rakyat, bertekad kuat membawa perubahan yang lebih baik. Rakyat butuh pemimpin yang mendengarkan tangisan pilu nasibnya dan mengulurkan tangannya untuk berdiri tegak bersama-sama dalam mengatasi masalah dengan asa kejujuran dan kepercayaan serta kerendahan dan kesederhanaan. Mencari pemimpin yang dapat mengendalikan dirinya, keluarganya, dan kerabatnya agar terhindar dari praktek hoaks, korupsi, kolusi, dan nepotisme. 
Bukanlah janji-janji yang dibutuhkan rakyat, namun pembuktian dan mewujudkan tujuan negara Indonesia sesuai Pembukaan UUD 1945 alenia ke-4 (detiknews, 13 Mei 2008,06.51WIB, Sosok pemimpin Indonesia yang dibutuhkan rakyat, mulya69@yahoo.com, 22/2/2019,17.12 WIB).

\section{BAB II. PEMBAHASAN}

Tulisan ini menggunakan metode penelitian kualitatif melalui studi literatur mengeksegesis teks Kisah Para Rasul (Kis. 4 :36-37;11:19-30), dengan mendeskripsikan kristalisasi kepemimpinan Barnabas.

\section{A. Arti Nama Barnabas (Kis. 4:36-37)}

Kisah Para Rasul 4 : 36-37 menyatakan “ Demikian pula dengan Yusuf, yang oleh rasulrasul disebut Barnabas, artinya anak penghiburan " (LAI). KJV menyatakan "And Joses, the one surnamed Barnabas the apostles, wich is, being translated, Son of Consolation". GNT

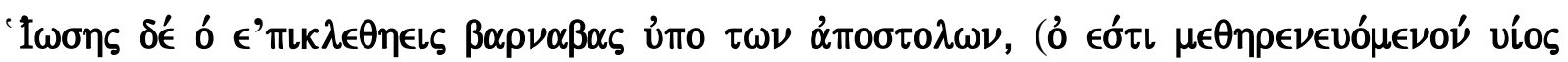
$\left.\pi \alpha \rho \alpha \kappa \lambda \epsilon^{\epsilon} \sigma \in \varsigma^{\prime}\right)$, (Jay P. Green, 1991) transkripsinya "Ioses de, ho epikletheis Barnabas upo ton apostolon (ho esti metherenenomeon, wios parakleseos)." Nama asli Barnabas adalah Yusuf, rasul-rasul menyebutnya Barnabas. Barnabas artinya "anak penghiburan”, seorang Yahudi suku Lewi dari Siprus. Setelah menjadi Kristen, ia menjual harta miliknya dan dipersembahkan kepada para rasul (Kis. 4:36-37). Namun, Lukas tidak bermaksud memberikan etimologi ilmiah, tetapi menunjukkan watak orang itu. Barnabas termasuk salah satu penggerak kebangunan rohani seorang yang rindu berbuat benar (F.D. Wellem, 2003).

\section{B. Barnabas Diutus Oleh Jemaat Yerusalem (Kis. 11: 22)}

Kisah Para Rasul 11 : 22 “...lalu jemaat itu mengutus Barnabas ke Antiohia”, (LAI).

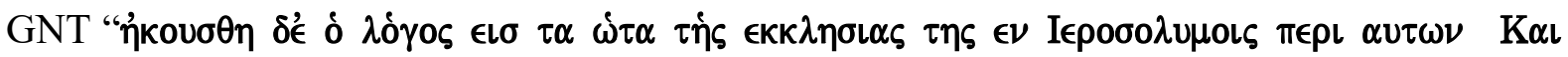

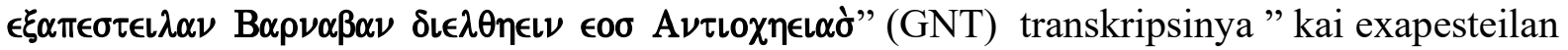
Barnaban dielthein eos Antiocheias.” Terjemahan KJV “...And they sent out Barnabas to go through as far as Antioch." (KJV). Kata penting di ayat 22 ini ialah terjemahan dengan

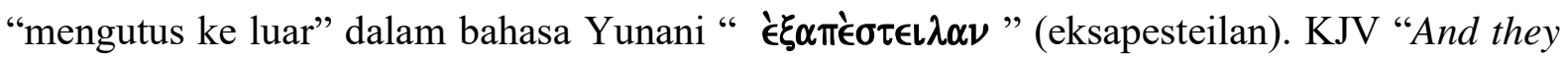
sent out Barnabas to go through as far as Antioch”. Klausa penting dalam ayat ini adalah 
"mengutus Barnabas ke Antiokhia, dimana kata"mengutus" dalam KJV "sent " ialah menjelaskan dimana Allah 'mengutus' anak-Nya (Gal.4:4). Dimana Allah 'mengutus' Roh Anak-Nya (Gal. 4:6 ; Luk. 24:49). Makna terbaik "pempo" lebih merupakan istilah lebih umum dari "apostello", yang maknanya "pengusulan resmi atau pengutusan di bawah wewenang" (Luk.1:53;20:10,11;Kis. 9:30;11:22;17:14). Dan pengutusan Barnabas oleh sidang jemaat Yerusalem berdasarkan "autentik" (Yun. "authentikos") artinya dapat dipercaya, asli, tulen atau sah. Sesuatu yang autentik jika sesuai dengan fakta apa yang dilihat, didengar dan dirasa sehingga dapat dipercaya. Selain itu, bona fide "jujur,dapat dipercaya", genuine "sejati, asli", real "riel, nyata, sejati", true "benar, betul", undoubted "tidak diragukan", unquestionable "tidak dapat disangkal" (W.E. Vine, dkk, 1985).

\section{Barnabas Melihat Kasih Karunia Allah (Kis 11: 23a)}

Kisah Para Rasul 11: 23 "Setelah Barnabas datang dan melihat kasih karunia Allah,”,

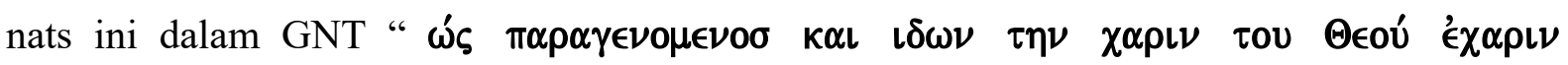
"transkripsinya "hos paragenomenos kai idon ten charin tou Theou,". KJV "who having come, and seeing the grace of God." Dua kata kerja yang penting yaitu kata "melihat" "idon" dan "bersukacita "Echarin”, yaitu kata "melihat", "Yunani “idon”, “ Inggris "seeing” menjelaskan melihat sesuatu yang benar atau jelas yang langsung terlihat oleh mata, dan terpampang nyata, menunjukkan penampilan luar, bentuk, dan dalam hal ini penggunaan maknanya untuk Roh Kudus dalam mengambil bentuk jasmaniah, seperti burung merpati (Luk. 3:22; 9:29). Kata "melihat" juga digunakan dengan referensi untuk setiap pribadi dalam Trinitas. Makna yang sama melekat pada pernyataan rasul tentang kita hidup dengan iman bukan dengan penglihatan "eidos" (2 Kor.5:7), dimana "eidos" makna melihat namun sesuatu yang tampak diatur agar kontras untuk sesuatu yang berhubungan langsung dengan iman. Orang percaya dibimbing, bukan hanya oleh sesuatu yang terlihat namun juga walau tidak terlihat. Barnabas orang yang melihat kasih karunia Allah. Allah lebih dari apapun, kasih karunia-Nya meruntuhkan segala tembok kesombongan, perbedaan, perselisihan, pemikiran. Kata "kasih karunia" ialah kasih kemurahan hati Allah kepada manusia berdosa yang tidak layak menerimanya (W.E.Vine,dkk : 1985).

\section{Barnabas Bersukacita (Kis. 11:.23b)}


Kata "bersuka cita", Yunani "ekhare", Inggris "rejoiced" berasal dari kata "chairo" ialah menjelaskan untuk bergirang atau bergembira atau bersukacita. Hal ini dimaksudkan bagi orang percaya di dalam Tuhan (Flp. 3:1;4:4), perwujudan-Nya (Luk. 1:14), kekuatan-Nya (Luk. 13:17), kehadiran-Nya dengan mereka (Yoh. 16:22); Kemenangan-Nya terakhir ( 8:56 ); mendengar penerimaan Tuhan (Luk. 19:6); namanya yang terdaftar di surga (Luk. 10:20); kebebasan mereka di dalam Kristus (Kis.15:31); pengharapan mereka (Rm. 12:12); upah mereka (Mat. 5:12); dan ketaatan dan kelakuan yang mencerminkan Tuhan dari persekutuan orang percaya (Rm.16:19). Barnabas seorang pemimpin rohani yang bersukacita atau merasa senang karena melihat keberhasilan atau kemajuan anggota jemaatnya dalam kehidupan pertumbuhan rohaninya. Pengaruh pemimpin membuat terjadinya perubahan, kehidupan anggota yang lebih baik, dan tercapainya visi organisasi. Memengaruhi adalah kemampuan pemimpin mengubah sikap, perilaku, pola pikir, pendapat, dan kesediaan bergerak ke arah pencapaian visi (W.E.Vine,dkk,1985). Sedangkan Tom Wright (2011 : 269) dalam bukunya "Kisah Para Rasul Untuk Semua Orang” menyatakan tentang penghormatan dr. Lukas terhadap Barnabas amat menyentuh dan sarat makna secara teologis : ia datang dan melihat kasih karunia Allah, dan bersukacita” . Jadi karena Barnabas memiliki karunia Allah (mampu melihat kasih karunia Allah), bukan saja Barnabas yang bersuka cita tetapi sekelompok besar memuji Allah, dan diajar tentang Yesus dan kitab suci, maka mereka dikuatkan dalam nasihat menjadi tetap setia kepada Tuhan Yesus.

\section{E. Barnabas Menasihati (Kis. 11: 23c)}

Ayat 23c "Ia menasihati mereka, supaya mereka semua setia kepada Tuhan" (LAI), terjemahan KJV "And he exhorted all with purpose of heart to abide near the Lord", dan GNT

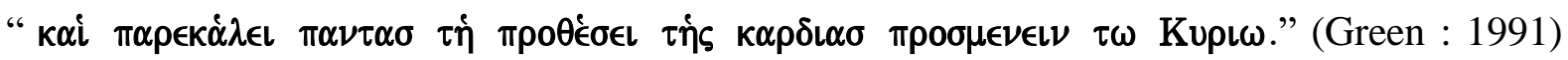
transkripsinya "kai parekalei pantas te prothesei tes kardias prosmenein to Kurio". Kata penting

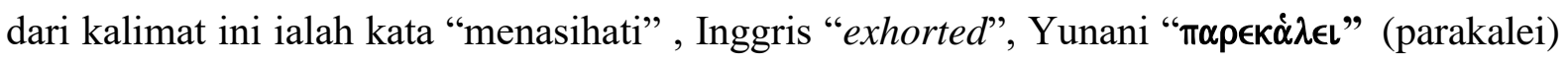
menjelaskan hal asal kata "parakaleo" artinya secara umum untuk memanggil seseorang (para kesamping, kaleo,memanggil), menunjukkan untuk memanggil dengan suara keras, memohon. Memperingatkan,mendesak, atau mendorong sesuatu atau seseorang untuk mendapatkan langkah atau arah mengerjakan (kemungkinan berhasil, memandang ke depan, berlainan makna dengan kenyamanan,berhubungan dengan waktu dan berhubungan dengan pengalaman diterjemahkan "beseech" (1 Tim.5:1), "intreat" (1 Tes. 5:11); "exhorted” (2 Kor.8:6, 12:18); 
“desire" (1 Tim.1:3) (W.E.Vine, dkk,1985). Sebab "menasihati" "parakalein" artinya memohon (Mat.8:5), mengajak orang yang belum seiman untuk percaya kepada Tuhan Yesus (2 Kor.5:20;1 Tes.2:3), juga menasihati dan saling menghibur di antara orang-orang yang sudah percaya Tuhan (Rm.12:1;Fil.2:1;2 Kor.2:7;1 Tes.4:18;Kol.4:8;Flm 7) (Robby Setiawan : 2004). Sedangkan B.F. Drewes ( 2014: 223) menafsir Barnabas "menasihati" ia melakukan tugas pastoral "parakaleo"; pemakaian di sini berkaitan dengan "paraklesis" (penghiburan), terdapat di Kisah Para Rasul 4:36 ini untuk menjelaskan namanya, ayat 19-21 dan ayat 22-24 juga diakhiri dengan tumbuhnya jemaat sebagai tanda berkat Tuhan. Salah satu tugas menggembala "menasihati” dilakukan melalui komunikasi antarpribadi.

\section{F. Barnabas Orang Baik (Kis. 11: 24)}

Kisah Para Rasul 11: 24 "karena Barnabas adalah orang baik" Nats ini dalam

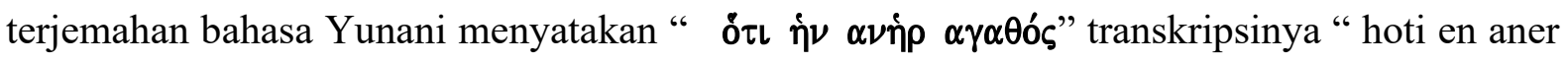
agathos”. KJV “ For he was o good man". Ayat ini menjelaskan keadaan pribadi Barnabas

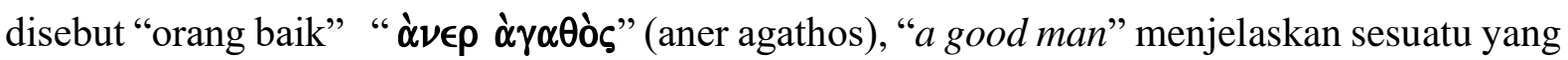
baik seperti karakter, jasmani, dan bermanfaat baik dari segi dampaknya, makna ini biasa digunakan dalam benda secara fisik, misal sebuah pohon (Mat. 7:17); tanah (Luk. 8:8). Selain itu, secara moral, biasanya tentang seseorang atau benda. Tuhan pada dasarnya, pastinya atau sepenuhnya, dan dengan sempurna adalah baik (Mat. 20:15;Mrk. 10:18;Luk. 18:19). Bagi orang-orang tertentu, kata yang digunakan di dalam (Mat. 20:15;Luk. 19:17;Yoh. 7:12); dalam penggunaannya secara umum (Mat. 5:45;Luk. 6:45;Rm.5:7;1 Pet. 2:18). Barnabas seorang yang baik penuh dengan kebajikan (benefiting others). Kebaikan Barnabas dimulai ketika membawa persembahannya ke hadapan para rasul, ia disebut "anak penghiburan" oleh para rasul "Kis. 4:36-37” (W.E. Vine, dkk, 1985).

\section{Barnabas Penuh Roh Kudus (Kis.11: 24)}

Ayat 24 “dan penuh oleh Roh Kudus”. Klausa “dan dipenuhi oleh Roh Kudus”, GNT “

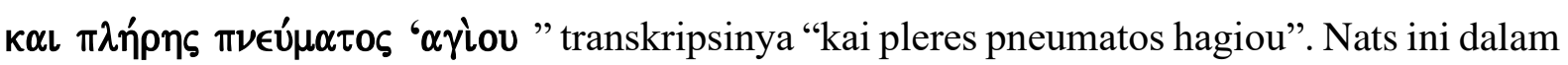
KJV “ and full of the Holly Spirit". Kata "pleres", "full” menjelaskan hal denotes "full” artinya menunjukkan "penuh" dalam pengertian dari menjadi dipenuhi, secara materi (Mat. 14:20; Mrk. 8:19) "keranjang yang penuh dengan roti"; dengan kusta (Luk. 5:12); secara spirit atau 
jiwa, oleh Roh Kudus (Luk. 4:1;Kis. 6:3); kasih karunia (Kis.6:8); dampak dari kehidupan spiritual dan kualitas, terlihat dari buah pekerjaannya yang baik (Kis. 9:3). Dalam pengertian telah menjadi utuh, seperti bulir yang telah terisi penuh (Mrk. 4:28); dari sebuah penghargaan atau upah di kehidupan kekal (2 Yoh. 8). Penuh Roh Kudus, karunia-karunia dan karakter, ketaatan pada Roh Kudus. Hidup yang berpusatkan pada Kristus sebagai Tuhan. Barnabas adalah pribadi yang 'netral', rendah hati (humble) dan sangat obyektif dalam menilai kondisi jemaat ini. Barnabas mewakili keterbukaan jemaat Yerusalem akan pimpinan Roh Kudus tentang pemberitaan Injil bagi bangsa-bangsa lain (W.E.Vine,dkk, 1985). Sedangkan Tom Wright menyatakan tentang penghormatan dr. Lukas terhadap Barnabas amat menyentuh dan sarat makna secara teologis : ia datang dan melihat kasih karunia Allah, dan bersukacita, karena ia adalah orang baik, penuh dengan Roh Kudus dan iman. Dengan kata lain, apa yang dilihat Barnabas bukan hanya sekelompok besar aneka manusia yang tampak meragukan, memenuhi rumah seseorang, memuji Allah, dan diajar tentang Yesus dan kitab suci.Dibutuhkan kerendahan hati dan iman untuk bisa melihatnya; Barnabas memiliki keduanya, berkat pekerjaan Roh Kudus di dalamnya (Tom Wright,2011).

\section{E. Barnabas Orang Beriman (Kis. 11: 24)}

Ayat 24 " dan iman" $\kappa \boldsymbol{\alpha} \iota \pi \lambda \eta ́ p \eta \varsigma ~ \pi \iota \sigma \tau \epsilon \omega \varsigma$ " transkripsinya "kai pleres pisteos" dalam KJV "and of faith", dimana kata "faith" dalam kata Yunani "pistis" ( menjelaskan "kepercayaan teguh", keyakinan atau kepercayaan yang berasal dari pendengaran (akin to peitho, "untuk meyakinkan", digunakan dalam Perjanjian Baru selalu untuk "iman" di dalam Tuhan atau Kristus dan hal spiritual lainnya). Kepercayaan Barnabas merupakan keyakinan yang teguh yang bersumber dari pendengaran akan Firman Allah yang disampaikan oleh rasul Petrus (bnd 1 Kor.1:9), maka berpengaruh kepada pertumbuhan gereja di Antiokhia (W.E.Vine, dkk,1985).

\section{F. Barnabas Mencari Saulus (Kis. 11: 25)}

Ayat 25 “...Barnabas ke Tarsus untuk mencari Saulus; dan setelah bertemu dengan dia,

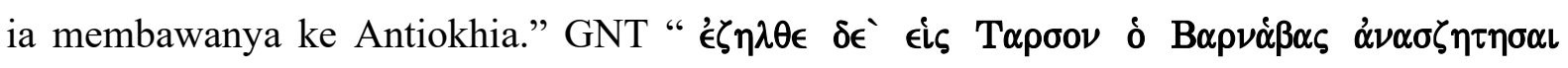

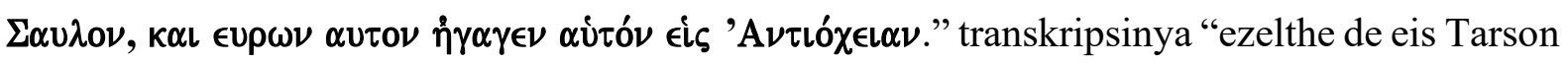
ho Barnabas anaszetesai Saulon, kai euron auton hegagen auton eis Antiocheian." KJV“ And 
Barnabas went out to Tarsus to seek Saul." Dalam kalimat ayat ini kata penting adalah "mencari

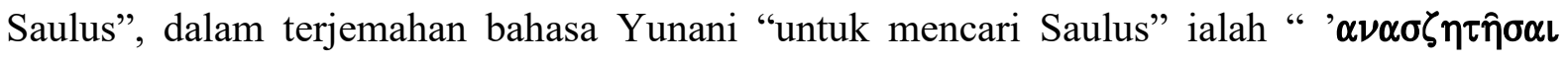
$\Sigma \alpha \cup \lambda o \nu "$ (anaszetesai Saulon) Kata "mencari” dalam bahasa Yunani "anaszetesai”, dalam bahasa Inggris "seek" berasal dari kata " $\alpha \nu \alpha \zeta \eta \tau \epsilon \omega$ ” (anazeteo) menjelaskan hal "to seek carefully" artinya "mencari dengan sungguh-sungguh" (ana, yang berarti "untuk mencari, atau untuk dicari” (Mat.2 : 20; 7:7,8;Luk. 24:5;Yoh. 6:24; Kis. 21:31). Secara metafora untuk mencari melalui berpikir, mencari, menelusuri, menelisik bagaimana melakukan sesuatu atau apa yang mau diperoleh. Untuk mencari Tuhan (Kis.17:27; Rm. 10:20); mencari Kerajaan Allah dan kebenarannya, dalam artian mendambakan atau merindukan dengan sungguh, berusaha keras (Mat. 6:33) ; hal-hal yang di atas (tentang sesuatu yang bukan duniawi, Kol. 3:1) (W.E.Vine,dkk, 1985).

Menurut Tom Wright (2011:269) Barnabas berpikir gereja di Antiokhia membutuhkan seseorang yang bisa mengajar, yang bisa memajukan pelayanan ini dan memberinya akar yang dalam serta serat-serat mental yang dibutuhkan. Ia berpikir, ia tahu siapa yang bisa melakukannya. Bagi Barnabas, membawa Saulus ke dalam suatu kelompok murid-murid yang sudah berkembang yang tidak didirikannya sendiri, pasti secara potensial juga sulit. Mungkin ada rasa tidak suka, ketidakcocokan kepribadian, dan hal-hal seperti itu. Barnabas memiliki integritas seorang yang baik, dipenuhi Roh Kudus, maka berpengaruh kepada sikap dan respon Saulus (Tom Wright,2011).

\section{G. Barnabas Tinggal Dengan Jemaat (Kis. 11: 26a)}

Ayat 26a "Mereka tinggal bersama-sama dengan jemaat itu satu tahun lamanya," dalam KJV "And it happened that many of them were gathered to them in the church a whole year."

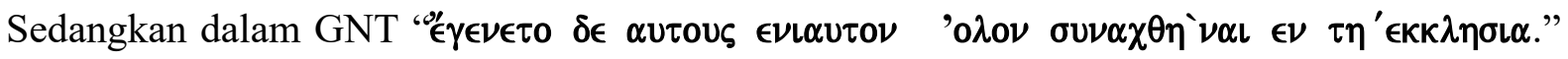
transkripsinya "Hegeneto de autous eniauton holon sunaxthenai en te ekklesia". Kata penting di dalam kalimat ini adalah kata "tinggal bersama-sama dengan jemaat", Inggris "gathered", "sunakh thenai" "assembled" artinya untuk berkumpul bersama dari orang (Mat. 2:4) dan benda (Mat. 13:30). Ayat 25-26, "lalu pergilah Barnabas ke Tarsus untuk mencari Saulus; dan setelah bertemu dengan dia, ia membawanya ke Antiokhia. Mereka tinggal bersama-sama dengan jemaat itu satu tahun lamanya, sambil mengajar banyak orang. Di Antiokhialah muridmurid itu untuk pertama kalinya disebut Kristen. Pemuridan yang dilakukan Barnabas dan Saulus, "tinggal bersama-sama”. Mengajar banyak orang, menghasilkan kualitas tertentu yang 
disebut "Kristen", dan menghasilkan orang-orang dengan kualitas 'pekerja Kristus' (Jay G. Green,1991). Selanjutnya, Young G. Chai mengatakan jemaat rumah adalah jemaat yang berkumpul di rumah dengan pemimpin orang awam. Pada jaman gereja mula-mula, orang awam mengabdikan diri seperti pendeta. Mereka menggembalakan jemaat dan jemaat berkumpul di rumah mereka. Salah satu contoh yang baik di antara orang-orang yang menggembalakan jemaat dengan sistem Jemaat Rumah adalah Priskila dan Akwila (bnd Kis.18 :1-3; Rm. 16:3-5a; Kol.4:15; Flm.1:1-2”). Dalam gereja rumah pemimpin tidak dipilih tetapi dilahirkan melalui pemuridan yang menitik beratkan pada karakter dan integritas seseorang. Dalam gereja rumah, rumah menjadi tempat penjangkauan keluar, kepemimpinan, persekutuan, dan pemuridan (Young G. Chai,2005).

\section{H. Barnabas Mengajar (Kis. 11: 26b)}

Ayat 26b "... mengajar banyak orang. Di Antiokhialah murid-murid itu untuk pertama kalinya disebut Kristen.” Terjemahan KJV “ they tought a considerable crowd. And diciples

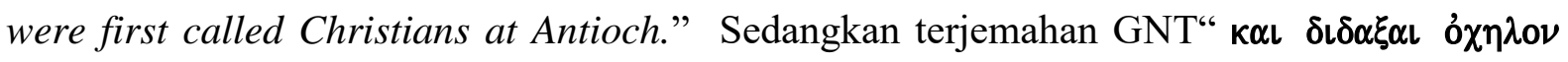

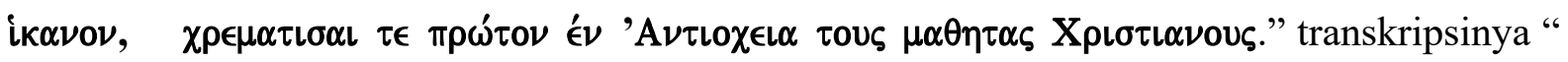
kai didaxai ochlon ikanon, chrematisai te proton en Antiocheia tous mathetas Christianous." Kata-kata penting terdapat dalam kalimat ini ialah kata "mengajar, murid-murid, Kristen", Yunani "didachai, mathetas, Christianous", dan Inggris "taught, disciples, Christians". Kata "taught" (didachai) berasal dari kata "didasko" artinya digunakan dengan jelas untuk memberikan instruksi (Mat. 4:23;Rm.12:7). Secara transitif, dengan obyek ataupun orang (Mat. 5:2), dan sering di dalam pengajaran dan Kisah Para Rasul (Mat.15:9;Kis. 15:35); baik orang maupun benda (Yoh.14:26; Why. 2:14,20). Kata "disciples" (mathetas) ialah berasal dari kata "mathetes" ialah menjelaskan "pembelajar" (asal "manthano", belajar, dari dasarnya atau akarnya, dimaksudkan pemikiran yang disertai dengan usaha, sedangkan didaskalos "guru". Hal ini menunjuk "seseorang yang mengikuti ajaran seseorang" seperti murid Yesus, dalam makna umum,orang Yahudi yang menjadi pengikut-Nya ( Yoh. 6:66;Luk. 6:17), beberapa secara diam-diam (Yoh. 19:38), terutama kepada 12 rasul (Mat. 10:1;Lukas 22:11), dan semua yang menunjukkan bahwa mereka adalah murid dengan mengikuti firman-Nya (Yoh. 8:31) (W.E.Vine,dkk,1985).

\section{Barnabas Memuridkan (Kis. 11: 26c)}


Di Antiokhialah murid-murid itu untuk pertama kalinya disebut Kristen (ay. 26c). Kata "Kristen" (Christianos) artinya sebuah kata yang terbentuk setelah mode atau gaya Roma, menandakan pengikut Yesus, yang digunakan bagi para kafir dan ditemukan di Kisah Para Rasul 11:26;28;1 Petrus 4:16. Walaupun kata “dipanggil” di dalam Kisah Para Rasul 11:26 digunakan sebagai nama yang diadopsi oleh seseorang atau diberikan dari orang-orang "Kristen” (Jay.P. Gree,1991). Sedangkan Tom Wright menyatakan Barnabas dan Paulus mengajar dengan tinggal bersama-sama dengan jemaat (ay.26). Tujuan Barnabas pergi ke Tarsus untuk mencari Saulus dan membawanya ke Antiokhia adalah untuk mengajar atau memuridkan orang-orang percaya baru di Antiokhia. Ia tahu Paulus adalah seorang guru dan pengkhotbah yang berbakat luar biasa dan ingin melihat bakat itu digunakan sepenuhnya. Barnabas bukan hanya mampu melihat bakat Paulus mengajar dan berkhotbah, agar digunakan sepenuhnya di jemaat Antiokhia (Tom Wright, 2011). Sedangkan B.F. Drewes (2014:225) tafsiran Alkitab "Kisah Para Rasul", menyatakan ayat 26 merupakan satu kalimat yang mulai dengan "dan terjadi" "egeneto", suatu fase baru dimulai dalam perkembangan jemaat Kristen. Barnabas menyadari bahwa setiap orang yang sudah diinjili harus diajar melakukan segala sesuatu yang telah diperintahkan Yesus kepada murid-murid-Nya (bnd Mat.28:20). Robby Setiawan (2004 : 87-88) menyatakan tujuan mengajar ialah supaya semua umat Tuhan makin menyerupai sifat -sifat Yesus. Mengajar bukan saja membagi pengetahuan secara akali saja tetapi "membagikan hidup", bukan sekedar teori belaka, tetapi sungguh-sungguh nyata di dalam kehidupan sang pengajar (bnd Mat. 7:28-29).

\section{J. Barnabas Peduli Sosial (Kis. 11: 29-30)}

Ayat 29, 30 "mengumpulkan suatu sumbangan dan mengirimkannya" dalam GNT $\dot{\omega} \rho\llcorner\sigma \alpha \nu \in \kappa \alpha \sigma \tau \sigma \varsigma \alpha U \tau o \nu \in \iota \varsigma \delta\llcorner\alpha \kappa o \nu \iota \alpha \nu$ transkripsinya "orisan ekastos auton eis diakonian", $\mathrm{KJV}$ “determined each of them for ministration", kata penting "ministration" $\delta\llcorner\alpha \kappa o \nu\llcorner\alpha \nu$, ialah menjelaskan artinya kantor dan pekerja, pekerja, melayani, adalah digunakan dari pengerjaan domistik, dan juga dari keagamaan dan pelayanan kerohanian. Melaksanakan "Diakonia", sepakat untuk menyisihkan uang dan mengumpulkannya bagi mereka yang membutuhkan (ay. 29,30), dan melaksanakan "Misi", dengan mengutus misionaris, sebab mereka menaati tuntunan Roh Kudus yang berbicara dalam pertemuan doa mereka untuk menyerahkan orangorang tertentu kedalam tangan Tuhan, untuk pekerjaan yang diembankan Tuhan kepada mereka (bnd. Kis.13:2-3). Kemurahan hati dalam ayat 29-30 merupakan wujud dari peduli kepada penderitaan orang lain, hal ini buah dari karunia "membagi-bagikan sesuatu dengan ikhlas “ 
(bnd Rm 12:8), dengan tulus ikhlas "haplotes" artinya kesederhanaan ataupun kemurahan hati, kata "kemurahan" "eleos", artinya memberi sedekah, "Samaria yang murah hati" (Luk.10:37; bnd Kis 4 : 36-37) (W.E.Vine,dkk,1985). Sedangkan Tom Wright (2011:271) menganggap narasi Kisah Para Rasul 11:29-30 cocok dengan Galatia 2 : 1-10, tidak akan terlalu keliru. Ia menjelaskan yang lebih penting tentu saja adalah gereja harus selalu terbuka terhadap jeritan orang-orang miskin, dari sudut manapun asalnya, dan harus selalu siap berespons dengan mengirimkan pertolongan serta orang-orang terbaiknya. Orang-orang "Kristen" pertama bukan hanya dikenal sebagai "umat raja" (Tom Wright, 2011).

\section{BAB III. RELEVANSI DALAM KONTEKS RAKYAT INDONESIA MEMILIH PEMIMPIN PADA PEMILU 2019}

Tahun 2019 ini disebut juga tahun politik, masa ini disibukkan dengan kampanye dari para calon pemimpin dari partai-partai yang lolos seleksi menjadi kontestan Pemilu. Rakyat mulai berpikir untuk memilih siapa yang layak menurutnya. Dengan segala upaya para candidat pemimpin di badan legislatif maupun di badan eksekutif bangsa Indonesia. Partai-partai bertarung dan bersaing untuk menarik simpatik dan menggiring masyarakat untuk tertarik dan memilih calon-calom pemimpin yang diusung oleh partai-partai yang lolos mengikuti Pemilu legislatif DPR,DPD, dan DPRD. Bahkan dari KPU dan Bawaslu dituntut sekelompok masyakarat agar mempublikasikan calon-calon dari masing-masing partai yang terindikasi kasus korupsi agar tidak dipilih oleh rakyat. Tujuannya agar rakyat Indonesia tidak salah memilih pemimpin pada Pemilu 2019 ini.

\section{A. Kepemimpinan}

\section{Pengertian Kepemimpinan}

Menurut Wirawan : kepemimpinan sebagai proses pemimpin menciptakan visi dan melakukan interaksi saling mempengaruhi dengan para pengikutnya untuk merealisasikan visi. Ia menjabarkan dalam enam cakupan yaitu : 1) proses, 2) pemimpin, 3) visi, 4) memengaruhi, 5) pengikut, dan 6) merealisasi visi. Menurut Hermawan ukuran keberhasilan dari kepemimpinan dan kepengikutan ditentukan oleh tercapainya visi (Wirawan, 2013). 


\section{Pendekatan Kepemimpinan}

Pendekatan sifat dalam kepemimpinan Barnabas terwujud ketika ia tinggal bersamasama dengan jemaat selama satu tahun di Antiokhia. Syaiful Sagala "Pendekatan dan model kepemimpinan" menyatakan satu pendekatan paling awal digunakan untuk penelitian kepemimpinan adalah pendekatan sifat (trait approach). Sifat atau ciri pemimpin menandakan bahwa pemimpin dapat memimpin oragnisasi secara efektif. Sifat-sifat yang dipelajari menurut Robbins dan Coulter (2010) adalah fisik, penampilan, golongan sosial, stabilitas emosi, kelancaran berbicara, dan kemampuan sosial. Pendekatan sifat ini mengemukakan ada karakteristik tertentu seperti daya fisik atau keakraban yang esensial bagi kepemimpinan, kepribadian, motivasi, nilai dan keterampilan yang menggambarkan sifat dari pemimpin. (Syaiful Sagala, 2018). Sedangkan David J. Hesselgrave dalam bakunya "Communicating Christ Cross Culturally" menyatakan pandangan David Berlo, tujuan utama kita dalam komunikasi adalah untuk menjadi seorang agen yang mempengaruhi, untuk mempengaruhi orang lain. (D.J. Hesselgrave, 2005).

\section{B. Integritas Pemimpin}

Dr. Lukas menyatakan secara jelas integritas Barnabas dengan menyebutnya sebagai orang baik, dipenuhi Roh Kudus dan iman (Kis.11:24). Integritas yang dimiliki seorang pemimpin sangat dibutuhkan dalam tugas pemimpin mengelola organisasi yang dipimpinnya. Syaiful Sagala menyatakan pemimpin harus cakap melakukan komunikasi interpersonal agar anggota organisasi tidak kehilangan arah. Seorang pemimpin yang memiliki integritas, kecakapan interpersonal yang tinggi dan menjunjung nilai-nilai kemanusiaan. Nilai, integritas, dan kecakapan interpersonal pemimpin tampak pada kemampuannya pada memberi dukungan, memperlakukan anggota tim dengan pantas, antusias dan peduli pada visi dan misi organisasi, berkomitmen tinggi menyelesaikan tugas dengan baik, rela belajar untuk kemajuan dan beorintasi kepada keteladanan dalam kata dan perbuatan (Syaiful Sagala, 2018).

\section{Pemimpin Yang Beriman}

Dalam konteks pemimpin di Indonesia, seorang pemimpin yang berintegritas ialah pemimpin memiliki iman kepada Allah. Sebab pemimpin yang memiliki iman merupakan 
pemimpin yang memiliki keyakinan atau kepercayaan dan tentunya ia akan senantiasa melayani, serta mengandalkan Allah. Sebagaimana Barnabas seorang yang baik, dipenuhi Roh Kudus dan iman. Pemimpin yang beriman menjelaskan seseorang yang dengan "kepercayaan teguh", keyakinan atau kepercayaan yang berasal dari pendengaran "akin to peitho", "untuk meyakinkan", digunakan dalam Perjanjian Baru selalu untuk "iman" di dalam Tuhan atau Kristus dan Roh Kudus. Anthony A. Hoekema dalam bukunya "Diselamatkan Oleh Anugerah" menyatakan pentingnya iman dalam diri seorang pemimpin diungkapkan begitu sering muncul baik iman dalam kata benda (pistis) maupun iman dalam kata kerja (pisteuein) dalam Perjanjian Baru sebanyak 240 kali. Tanpa iman mustahil orang dapat berkenan kepada Allah (Ibr.11:6). Iman merupakan "karya" luar biasa yang dituntut Allah bagi orang percaya (Yoh.6:29). Pistis dapat dipergunakan dalam pengertian "iman yang dengannya kita mempercayai atau iman yang diyakini (fides quae creditur), lihat Kisah Para Rasul 11:24 (Anthony A. Hoekema,2004).

W.T. Stace (1952 :107-108) di dalam bukunya Religion and Modern Mind memikirkan panjang lebar evolusi pikiran manusia dari keyakinan yang umum bahwa dunia merupakan satu urutan moral ke kepercayaan yang meluas dimana manusia adalah "orangorang penentu moral". Oleh karena itu, Stace mengemukakan bahwa "kehilangan iman religius mengharuskan substitusi etika sekular yang didasarkan pada tujuan-tujuan untuk etika berdasar konsepsi-konsepsi religius.

\section{Pemimpin Yang Baik}

Pemimpin yang baik merupakan pemimpin yang mengaplikasikan iman, pengharapan dan kasihnya dalam kehidupan khususnya pada tugas kepemimpinannya. Pemimpin Gereja Methodist Indonesia yang baik akan memberikan teladan yang dapat dilihat dan dirasakan pengikutnya. Pemimpin yang berintegritas adalah pemimpin yang baik. Myles Munroe (2002: 111-113) dalam bukunya "The Spirit of Leadership" menyatakan tentang "integritas". Atribut dari Tuhan adalah Mahakuasa, Mahatahu, Mahahadir dan integritas. Atribut keempat dari Tuhan adalah integritas-Nya yang absolut. Ini berarti bahwa Tuhan selalu murni dalam motivasi dan maksudnya. Para pemimpin sejati adalah orang yang jujur. Tidak ada manipulasi atau tipu daya dalam urusan mereka dengan orang lain atau pengajaran mereka akan visi mereka. Para pemimpin sejati selalu terus terang dan memiliki pengertian akan diri sendiri. Mereka setia kepada diri sendiri lebih dahulu dan kemudian kepada orang lain (Myles Munroe, 2002).

Glen H. Stassen dan David P. Gushee (2008: 646) dalam buku "Etika Kerajaan" menjelaskan praktik perbuatan baik dengan mengutif ungkapan teolog Yahudi Irving 
Greenberg menulis : "Esensi agama adalah apa yang dipraktikkan agama itu - selebihnya hanyalah omong kosong". Barnabas sebagai pemimpin yang baik hidup pada gereja mulamula melakukan kebaikannya dalam wujud mempersembahan hasil menjual ladangnya (Kis. 4: 36-37). Pemimpin yang dapat dipercaya karena ia adalah orang yang baik. Reputasi yang baik memang sangat berharga. Para penulis tentang integritas menunjukkan bahwa kebajikan ini terdiri dari banyak kualitas kejujuran, loyalitas, kesetiaan, kehormatan, keterbukaan, keadilan, kebaikan hati, kesungguhan. Berbagai kualitas ini dapat ditangkap melalui sosok panutan yang patut dicontoh dan pelatihan oleh para pemimpin dan penasihat moral. Namun semuanya itu juga dapat diajarkan (Antony D’Souza,2007).

\section{Kompetensi Pemimpin}

\section{Pemimpin Visioner}

Burt Nanus (2001: xv,13) dalam bukunya Kepemimpinan Visioner menyatakan di kota-kota, gereja, sekolah,pengadilan, rumah sakit, museum, dan lembaga-lembaga lainnya tampak sangat membutuhkan pemimpin visioner yang akan mengarahkan mereka, para pemimpin yang ulet dan percaya kemampuannya, berani mengambil risiko, lugas dan bersemangat, serta mampu memberikan inspirasi dan dorongan. Dengan tegas dan lugas Burt Nanus menyatakan, “Tak ada mesin penggerak organisasi yang lebih bertenaga dalam meraih keunggulan dan keberhasilan masa depan, kecuali visi yang menarik, berpengaruh, dan dapat diwujudkan, serta mendapat dukungan luas." Nanus menjelaskan kepemimpinan visioner dengan meminjam pepatah Cina kuno yang mengatakan ” bahwa jika anda tidak mengubah arah, maka anda pasti akan sampai ketujuan anda”. Bahkan Nanus memakai pernyataan Kouzes dan Posner yang mengatakan ," Orang-orang yang memimpin adalah barisan terdepan yang memperjuangkan perubahan. Nanus selanjutnya menjelaskan tentang hahekat kepemimpinan dengan mengatakan bahwa ciri-ciri kepemimpin sebagai berikut : Pemimpin mengemban tanggungjawab, mengusahakan pelaksanaan tugas, memiliki impian dan menterjemahkan menjadi kenyataan. Pemimpin dilihat dari aspek visi, rohani atau disiplin

rohani, karakter dan kompetensi. Sen Sendjaya menjelaskan bahwa masalah karakter lebih esensial ketimbang masalah kompetensi. Kemampuan membuat seseorang menuju puncak jabatan, tetapi karakter membuat sesorang bertahan di sana (Sen Sendjaya, 2012 ).

\section{Pemimpin Mereproduksi Pemimpin}


Kompetensi kedua yang penting dimiliki dalam kepemimpinan di Indonesia ialah pemimpin yang cakap mereproduksi pemimpin, istilah lain kaderisasi. Sebab pemimpin yang memiliki kecakapan mereproduksi pemimpin akan melahirkan pemimpin-pemimpin regenerasi yang baik. John C. Maxwell dan Jim Dorman (2007: 202-203) dalam buku mereka "Becoming a Person of Influence" menyatakan tentang beberapa manfaat menciptakan pemimpin (mereproduksi) di dalam organisasi yang tidak saja mengikuti Anda, tetapi juga mempengaruhi orang lain dan membina mereka. Sebab mereproduksi pemimpin menaikkan pengaruh Anda ke tingkat yang baru, mereproduksi pemimpin menaikkan potensi pribadi pemimpin baru, mereproduksi pemimpin melipatgandakan sumber daya, dan mereproduksi pemimpin memastikan masa depan yang positif untuk organisasi Anda.

\section{Pemimpin Cakap Mengajar/Menasihati}

Kompetensi ketiga yang penting dimiliki dalam kepemimpinan di Indonesia ialah pemimpin yang memiliki kecakapan mengajar dan menasihati. Sebab kompetensi ini akan melahirkan pemimpin-pemimpin yang terampil atau handal dalam mengajar kebenaran serta menjadi penasihat yang baik. David J. Hesselgrave dalam bakunya "Communicating Christ Cross Culturally" menyatakan pandangan David Berlo, tujuan utama kita dalam komunikasi adalah untuk menjadi seorang agen yang mempengaruhi, untuk mempengaruhi orang lain, lingkungan fisik kita, dan diri kita, dan untuk menjadi seorang agen yang menentukan, untuk memiliki satu suara dalam bagaimana segala sesuatu itu. Singkatnya, kita berkomunikasi untuk mempengaruhi - untuk mempengaruhi dengan sungguh-sungguh (Hesellgrave, 2005).

Syaiful Sagala (2018:222) dalam bukunya "Pendekatan \& Model Kepemimpinan" menyatakan seorang pemimpin memiliki integritas, kecakapan interpsersonal yang tinggi dan menjunjung tinggi nilai-nilai kemanusiaan. Nilai, integritas, dan kecakapan interpersonal pemimpin tampak pada kemampuannya mengajar atau menasihati untuk memberi dukungan dan tidak menjatuhkan orang, tidak memaksakan pandangannya, tidak terobsesi dengan efisiensi yang berlebihan, antusias dan peduli pada visi dan misi organisasi, memperhatikan etika tinggi dan dapat dipercaya, memiliki stabilitas emosi yang terkendal, mau belajar dari kesalahan, dan mencoba mengambil resiko, untuk membangun hubungan efektif, menerima perubahan sebagai sesuatu yang tidak bisa dielakkan, beorintasi pada aksi dan berkomitmen memimpin dengan memberi teladan dengan keberhasilan yang cemerlang. 


\section{Bab 4. PENUTUP}

\section{A. Kesimpulan}

Tulisan tentang kristalisasi kepemimpinan Barnabas dan relevansi dalam konteks rakyat Indonesia memilih pemimpin pada Pemilu 2019, dengan kesimpulan sebagai berikut :

1. Berdasarkan kajian eksegesis Kisah Para Rasul 4 : 36-37 ; 11:19-30 diperoleh pemikiran teologis kristalisasi kepemimpinan Barnabas patut menjadi pendekatan dan model kepemimpinan karena : Barnabas pemimpin yang diutus (autentik) dari jemaat Yerusalem untuk melayani di Antiokhia. Ia dikaruniakan Allah suatu karisma (kemampuan melihat kasih karunia Allah), hal itu membuatnya bersukacita. Sebagai pemimpin (Gembala) ia giat menasihati mereka orang percaya baru (maupun yang belum percaya) agar mereka tetap setia (percaya) kepada Tuhan Yesus. Barnabas memiliki integritas yang jelas, Lukas memberikan status sebagai orang baik, dipenuhi Roh Kudus (seseorang yang taat penuh kepada otoritas atau kedaulatan Allah/Roh Kudus atas dirinya) dan ia seorang yang beriman kepada Allah. Hal ini membawa pengaruh kepada sejumlah orang dibawa kepada Tuhan. Oleh karena Barnabas dipenuhi Roh Kudus dan iman menjadikannya seorang pemimpin yang transformasional dan pemimpin yang visioner. Buktinya ia ia pergi ke Tarsus untuk merekrut Saulus menjadi tim pemimpin bagi jemaat Antiokhia. Ia mampu mengetahui komptensi Saulus khususnya dalam mengajar. Mengajar adalah suatu aktifitas pemuridan dan juga penginjilan. Dari kegiatan tim kepemimpinan ini menghasilkan dampak kepada lingkungan di luar Antiokhia. Pada masa kepemimpinan Barnabas dan Saulus komunitas orang percaya disebut Kristen. Kemasyuran jemaat Antiokhia dibuktikan juga dalam kepedulian mereka kepada kesusahan orang-orang atau jemaat di Yudea, sehingga jemaat ini mengutus Barnabas dan Saulus untuk membawa sumbangan yang mereka kumpulkan.

2. Kristalisasi kepemimpinan Barnabas dapat dijadikan pendekatan dan model kepemimpinan dalam konteks rakyat Indonesia memilih pemimpin baik Presiden dan wakil presiden, serta para anggota DPR, DPD, DPRD pada Pemilu April 2019 yang sudah mendekat ini. 


\section{B. Saran}

1. Diperlukan cara yang tepat untuk mengetahui "rekam jejak" para candidat kontestan Pemilu. Karena itu rakyat tidak asal memilih apalagi hasil rayuan dengan kebohongan tentang siapa yang akan diplihnya baik untuk pemilihan presiden dan wakilnya maupun anggota DPR, DPD, dan DPRD di seluruh wilayah Indonesia.

2. KPU atau Bawaslu sebagai penyelenggara dan pengawas Pemilu kiranya terus secara aktif menginformasikan kepada masyarakat lewat media televisi maupun gadget atau surat kabar, agar masyarakat mendapatkan data atau sejenis cirruculumvitae dari para candidat di setiap daerah Pemilu, sehingga masyakarat bisa menentukan pilihanya dengan tepat berdasarkan pertimbangan tertentu yang sesuai norma-norma hukum di negara kita maupun sesuai norma-norma kepercayaannya.

3. Perlu diingatkan kepada seluruh masyarakat Indonesia hendaknya menggunakan hak politiknya dengan bijaksana, dan dihindari menjadi Golput. Selain itu, agar berhati-hati dan tidak mudah dikelabui dengan iming-iming diberikan materi atau jabatan tertentu agar memilih para candidat tersebut. 


\section{KEPUSTAKAAN}

Barna,Geoge. Leaders on Leadership. Malang : Gandum Mas, 2002.

Brink, D.v.d.Tafsiran Alkitab Kisah Para Rasul. Jakarta : BPK Gunung Mulia, 1996

Budyatna,Muhammad. Teori Komunikasi Antarpribadi. Jakarta : Prenadamedia Group, 2011

Chai, Young G. Jemaat Rumah. Jakarta : Glory Cipta Grafika, 2005

Drewes,B.F. Tafsiran Alkitab Kisah Para Rasul, Jakarta : BPK Gunung Mulia, 2014

D’Souza,Anthony, Proactive Visionary Leadership . Alih bahasa : Lilis Setyanti. Jakarta : PT. Trisewu Nagawarsa,2007

Green, Jay P. The Interlinear Greek-Englis New Testamen. Massachusetts : Hendrikson Publisher, 1991

Hoekema, Anthony A., Alkitab dan Akhir Zaman. Alih bahasa : Kalvin S.Budiman.Surabaya : Momentum, 2004

Hesselgrave, David.J. Communicating Christ Cross Culturally.Michigan : Grand Rapids, 2005

Maxwell, John C. dan Jim Dorman. Becoming a Person of Influence. Jakarta : Harvest Publication House, 2007

Munroe, Myles. The Spirit Of Leadership. Alih bahasa : Budijanto. Jakarta : Immanuel, 2002

Nanus,Burt. Kepemimpinan Visioner. Jakarta : PT.Prenhallindo,2001

Northouse,Peter G. Kepemimpinan.Jakarta : PT. Indeks,2013

Sagala, Syaiful. Pendakatan \& Model Kepemimpinan.Jakarta : Prenadamedia,2018

Sendjaya,Sen. Jadilah Pemimpin Demi Kristus.Jakarta : Perkantas, 2012

Setiawan,Roby. Lebih dalam Mengenal Roh Kudus, Semarang : Setiawan Literatus Ministry, 2004

Sutanto, Hasan.Perjanjian Baru Interlinear dan Konkordansi Perjanjian Baru (PBIK), Jilid I, Jakarta : LAI 2003

Stace,W.T. Religion and Modern Mind. Philadelpia : Lippincott,1952

Stassen,Glen H. \& David P. Gushee. Etika Kerajaan. Surabaya : Momentum, 2008

Wirawan, Kepemimpinan.Jakarta : PT.Raja Grafindo Persada, 2013 
Wright, Tom.Kisah Para Rasul Untuk Semua Orang.Jakarta : Perkantas Divisi Literatur,2011

Vine,W.E.,Merrill F. Unger,William White,Jr. Vine's Complete Expository Dictionary Of Old And New Testament Words.Nashville Camden New York : Thomas Nelson Publishers, 1985

Disarikan menjadi artikle berjudul "Kelebihan Gereja Rumah Dibandingkan dengan Gereja

Tradisional" sumber : http://www.kristenonline.com/download/book/komsel.doc

http://gerejaperjanjianbaru.blogspot.com/2008/01/gereja-rumah.html, 30/1/2019,14.27 